\section{CPS-381 PROACTIVE MEDICATION RECONCILIATION AND PATIENT FLOW IN THE EMERGENCY DEPARTMENT ADMISSIONS}

${ }^{1} \mathrm{C}$ Hanlon*, ${ }^{2}$ S Mccarthy, 'D Lynch. 'Cork University Hospital, Pharmacy, Cork, Ireland;

${ }^{2}$ University College Cork, School of Pharmacy, Cork, Ireland

10.1136/ejhpharm-2021-eahpconf.213

Background and importance Pharmacist led medication reconciliations (MR) are the most exhaustive and accurate MRs. ${ }^{1-4}$ Proactive MRs have shown several clinical and statistical benefits over retroactive MRs, particularly in improving patient flow. $^{5}$

Aim and objectives To determine the feasibility of proactive pharmacist led MRs during emergency department (ED) admission and the patient flow impact.

Material and methods This was a mixed method feasibility study: quantitative prospective study of retroactive versus proactive $\mathrm{MRs}$ in the $\mathrm{ED}$; qualitative semi-structured interviews with ED nurses and doctors and admitting doctors. Within the pre-determined feasibility domains of acceptability, demand, integration and practicality, major themes were determined as described in the results.

Results

Acceptability Qualitative: All interviewees thought pharmacists should lead MRs and considering the service had a positive impact on workflow.

Quantitative: Pharmacists utilised a greater number of and more accurate medication information sources versus other healthcare professionals. Workflow improved, saving up to 19.5 min per proactive MR.

Demand Qualitative: Many thought we could reduce the amount of MRs completed and subsequently not admitted through targeting more complex patients. Improved prescribing and reducing late/missed doses were significant themes. Most used the service when available.

Quantitative: The number of MRs completed increased from 5.2 to 8.6 per day. $20 \%$ of proactive MRs were subsequently not admitted. $80 \%$ of retroactive MRs detected an error. Time from presentation to MR completion was reduced from 20.5 to 2.5 hours.

Integration Qualitative: Staffing and costs were considered barriers to integration. Targeted approach, integrated into admissions and linking with the medication flow technician service was preferred. Face-to-face communication was preferred.

Quantitative: Project saves were up to 19 077.18€/year (excluding error avoidance savings).

Practicality Qualitative: Most stakeholders were aware of the project despite difficulty spreading information. MR location/ layout was suitable. Admitting doctors looked for MR information within the clinical notes and ED doctors within the ED notes.

Conclusion and relevance This study demonstrated that pharmacist led proactive MRs in the ED were feasible and cost effective. It should be integrated into admissions after triage, with the aim of targeting more complex patients.

\section{REFERENCES AND/OR ACKNOWLEDGEMENTS}

1. Galvin, et al. Clinical pharmacist's contribution to medication-reconciliation on admission. Int J Clin Pharm 2013;35:14.

2. Grimes, et al. Relative accuracy and availability of an Irish National Database of dispensed medication. J Clin Pharm 2013;38(3).

3. Bell, et al. Association of ICU or hospital-admission with unintentional discontinuation of medications. JAMA 2011;306:840-7.
4. Grimes, et al. Collaborative pharmaceutical-care in an Irish hospital. BMJ 2014:25:574-83.

5. Renet, et al. Implementation of proactive medicines-reconciliation to reduce drug errors. EJHP 2015;22A168-A.

Conflict of interest No conflict of interest

\section{CPS-382 IMPACT OF A CLINICAL PHARMACIST AT TRANSITION OF CARE: A PROSPECTIVE STUDY IN AN ORTHOPAEDIC WARD OF A REGIONAL HOSPITAL}

${ }^{1} \mathrm{C}$ Reimer ${ }^{*},{ }^{2} \mathrm{~N}$ Gillard, ${ }^{3} \mathrm{AL}$ Sennesael, ${ }^{4} \mathrm{E}$ Deflandre, ${ }^{2} \mathrm{P}$ Anrys, ${ }^{2} \mathrm{~S}$ Demaret. ${ }^{1}$ Université Catholique De Louvain, Faculté De Pharmacie et Sciences Biomédicales, Brussels, Belgium ${ }^{2}$ Clinique Saint-Luc Bouge, Pharmacie, Namur, Belgium; ${ }^{3}$ Chu Ucl Namur, Pharmacie, Dinant et Godinne, Belgium; ${ }^{4}$ Clinique Saint-Luc Bouge, Anesthésie et Réanimation, Namur, Belgium

\subsection{6/ejhpharm-2021-eahpconf.214}

Background and importance Transition of care (TOC) is a high risk period for medication errors. Discrepancies and incomplete medication information are common on hospital admission and discharge, potentially leading to drug related problems and adverse drug events at TOC.

Aim and objectives The objectives of this study were to identify discrepancies on admission and at discharge and to detect the completeness of medication information in the discharge documents; and to assess the potential clinical impact of discrepancies.

Material and methods A 4 week prospective interventional study was carried out in a 29 bed orthopaedic surgery ward of a regional hospital. On admission, the pharmacist compared his best possible medication history to previous medication histories and to prescriptions to identify discrepancies. They were classified by type, ATC classes and level of risk for the patient. Risk was evaluated by one physician and one clinical pharmacist assessing potential clinical impact and likelihood of occurrence. At discharge, completeness of medication related information in discharge letters and prescriptions was analysed. Discrepancies between inpatient treatment and discharge prescriptions were reported and their clinical impact was evaluated.

Results 94 patients were included. On admission, 331 discrepancies with the previously recorded medication history were observed in 81 patients (92\%). Regarding prescriptions, there were 97 unintentional discrepancies that impacted 41 patients (43.6\%). Among these, 38 discrepancies (39.2\%) were classified as high or extreme risk and involved psycholeptics, antidiabetic drugs and antithrombotic agents. Omission was the most common discrepancy.

At discharge, 36 patients (40.4\%) had at least a high or extreme risk discrepancy. Patients had a risk of treatment duplication. Antithrombotic agents were a major class in which patients were at extreme risk. Only $60 \%$ of drugs prescribed were found in the discharge letters.

Conclusion and relevance Discrepancies and incomplete medication information are real issues at TOC. To improve patient care, the hospital pharmacist is a suitable and valuable healthcare professional.

\section{REFERENCES AND/OR ACKNOWLEDGEMENTS}

Conflict of interest No conflict of interest 